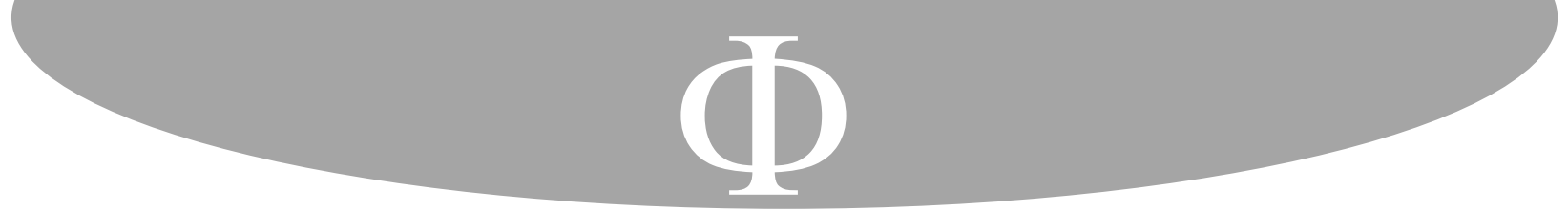

\title{
El talante de los líderes presbiterianos en Colombia*
}

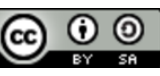

Para citar este artículo: Ramírez Suárez, Luis Eduardo. «El talante de los líderes presbiterianos en Colombia». Franciscanum 177, Vol. 64 (2022): 1-36.

\section{Resumen}

El presente artículo explora cómo la Iglesia Presbiteriana en Colombia forjó su propia identidad como iglesia reformada, manteniendo características y adoptando cambios en su identidad y misión. Esta presentación se da mediante una investigación bibliográfica, documental y un análisis en la formación de los actores y las comunidades, sus prácticas, imaginarios y representaciones. Pone especial énfasis en el papel que jugaron los misioneros, la formación del liderazgo local, el talante de la mujer presbiteriana y la expresión regional del presbiterianismo, en la identidad que forjó el presbiterianismo colombiano, en un ambiente de confrontación religiosa y resistencia.

\section{Palabras clave}

Protestantismo, Iglesia Presbiteriana, Misionero, Persecución religiosa, Teología de la Liberación.

\section{The character of Presbyterian leaders in Colombia}

\begin{abstract}
This article explores how the Presbyterian Church in Colombia forged its own identity as a Reformed church, maintaining characteristics and adopting changes in its identity and mission. This presentation is given through bibliographic and documentary research and an analysis in the formation of the actors and communities, their practices, imaginaries and representations. It places special emphasis on the role played by missionaries, the formation of local leadership, the character of Presbyterian women and the regional expression of Presbyterianism, in the identity that Colombian Presbyterianism forged, in an environment of religious confrontation and resistance.
\end{abstract}

\footnotetext{
* Este trabajo ha sido producto de la investigación para la tesis doctoral en historia en la Universidad Nacional de Colombia - Sede Medellín, que lleva por título: «Una historia de la Iglesia Presbiteriana en Colombia, 19561993», dirigida por el Dr. Gabriel Cabrera Becerra.

** Magister en teología del Seminario Bíblico de Colombia y Doctor en Historia de la Universidad Nacional de Colombia, Sede Medellín. Rector de la Fundación Universitaria Seminario Bíblico de Colombia, Medellín Colombia. ORCID 0000-0001-5187-9412. Contacto: rectoria@unisbc.edu.co.
} 


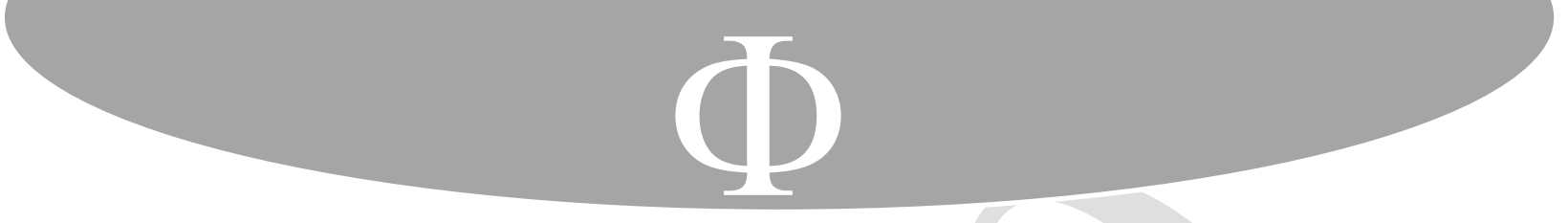

humano presbiteriano puede entrar en esta categoría de hombre religioso, que es guiado por un propósito de vida y misión, donde su quehacer responde a convicciones innegociables y por eso son portadores de un talante aguerrido y persistente. Ese talante se va a ver reflejado en el liderazgo presbiteriano, lo que se conoce como «carisma» ${ }^{5}$. Es Max Weber quien introduce el concepto de Dominación Carismática, como devoción afectiva a la persona que es dotada con facultades extracotidianas como: «facultades mágicas, revelaciones o heroísmo, poder intelectual u oratorio» ${ }^{6}$. En el presbiterianismo se desarrolló desde sus inicios un liderazgo carismático. La combinación de convicción y carisma en el liderazgo permitió el desarrollo una clase de ser humano que resistió el medio hostil donde se establecía el presbiterianismo en Colombia.

La Iglesia Presbiteriana colombiana fue influenciada por diferentes expresiones del presbiterianismo mundial. La vertiente escocesa legó al presbiterianismo dos clases de ministros ${ }^{7}$ : los «evangélicos» que se enfocaron en la vida consagrada, la evangelización, el cuidado de las almas, el encuentro personal con Cristo y en vivir una vida acorde con el mensaje del Evangelio; y los «moderados» que propendían por una fe cristiana que se relacionara con la sociedad, por la búsqueda de un alto nivel intelectual y por la formación de buenos ciudadanos ${ }^{8}$. Otras expresiones del presbiterianismo que llegaron de los Estados Unidos fueron: los puritanos, los teólogos de Princeton y los culturalistas holandeses ${ }^{9}$. Las tres expresiones diferían en relación a su concepción de la Escritura. Para los primeros la Biblia brindó la posibilidad de reflexión sobre la realidad espiritual, la conversión y la transformación del ser, pero puso poco énfasis en cómo estas enseñanzas se relacionaron con

sistema político. En el fondo de su corazón lo impulsa aquel sentimiento que animaba a Pablo cuando decía: ¡ay de mí si no anunciare el Evangelio!».

${ }^{5}$ Max Weber, Sociología de la religión, $2^{a}$ edición, Trad. Ariel Navarro (México: Ediciones Coyoacán, 1999), 41: «En las consideraciones ulteriores el término "carisma" será entendido como referencia a una cualidad extraordinaria de una persona, prescindiendo de que ésta sea real, presunta o supuesta. De este modo, la "autoridad carismática" aludirá a un poder sobre los hombres, ya sea primordialmente interna o externo, al cual se subordinan los gobernados en virtud de su fe en la cualidad excepcional de la persona específica. (...) La legitimidad de su mando se funda en la fe y la devoción por lo extraordinario, estimado en la medida en que sobrepasa las cualidades humanas normales, y considerado originalmente como sobrenatural (...). El alimento de esta fe es la "demostración" de la cualidad carismática por medio de milagros, triunfos y otras hazañas, es decir, mediante el bienestar de los gobernados».

${ }^{6}$ Max Weber, Economía y sociedad. Esbozo de sociología comprensiva, Trad. José Medina Echavarría, Juan Roura Farella, Eugenio Ímaz, Eduardo García Maynez y José Ferrater Mora (México: Fondo de Cultura Económica, 1999), 711-712; Bronislaw Bazcko, Los imaginarios sociales (Buenos Aires: Editorial Nueva Visión, 1991), 22-23.

${ }^{7}$ Juan A. Mackay, El sentido presbiteriano de la vida: lo que significa vivir y adorar como presbiteriano, 180. ${ }^{8}$ Juan A. Mackay, El sentido presbiteriano de la vida: lo que significa vivir y adorar como presbiteriano, 180186; Juan A. Mackay, Las Iglesias Latinoamericanas y el Movimiento Ecuménico (New York: CCAL, 1963), 22.

${ }^{9}$ George M. Marsden, «Introduction: Reformed and American», en Reformed Theology in America. A History of its Modern Development, ed. David F. Wells (Grand Rapids: Baker Books, 1997), 1-12; Elizabeth T. Adams, «Divided Nation, Divided Church: The Presbyterian Schism, 1837-1838», Historian 4, Vol. 54 (1992): 683696; George M. Marsden, «Introduction: Reformed and American», 9-10; Henry Zwaanastra, «Louis Berkhof», en Reformed Theology in America. A History of its Modern Development, ed. David F. Wells (Grand Rapids: Baker Books, 1997), 135-153. 


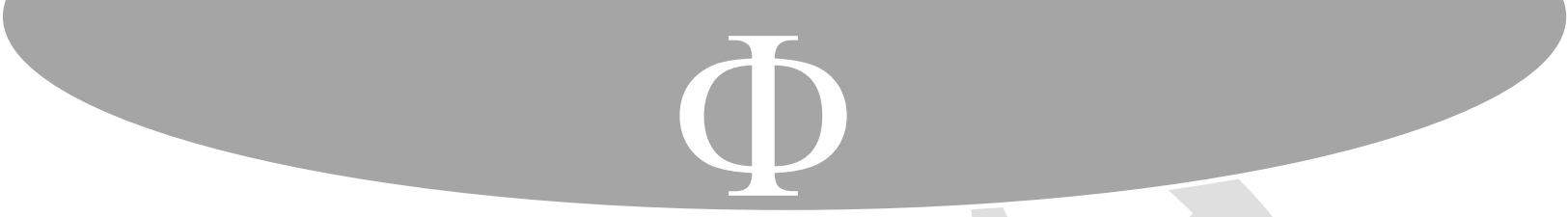

impulso a la obra editorial con la creación del periódico de publicación mensual $E l$ Evangelista Cristiano, que imprimió su primera edición en diciembre 1912; en 1925 se le cambio el nombre por El Evangelista Colombiano en tributo al pequeño boletín que publicaba irregularmente en Medellín el Rev. Juan G. Touzeau en 189125; el periódico tuvo más de 400 números, a lo largo de más de $\mathrm{XXX}$ series $^{26}$. Este fue un acontecimiento de profunda repercusión para la promoción del mensaje protestante; cabe recordar que en el siglo XIX y entrado el siglo XX la prensa era el principal medio de expandir las ideas. Las casas editoriales desde los tiempos del antiguo régimen eran muy escasas, debido a la censura que no permitía la libre imprenta. Entonces una de las formas de circular las ideas se suplía con la impresión de periódicos ${ }^{27}$. El Rev. Allan supo aprovechar este medio para suplir la carencia de la producción literaria protestante en Colombia, convirtiéndose en un visionario de la comunicación masiva de la fe. Sin embargo, es importante tener en cuenta que desde el tiempo del gobierno del general Santander hasta mediados del siglo XX Colombia tuvo tasas muy altas de analfabetismo, y enfrentó un proceso lento y complicado para contrarrestarlo ${ }^{28}$. Esto evidencia la importancia de la educación en la labor de los presbiterianos, porque saber leer era un paso indispensable para el crecimiento de su fe, que dependía de entender la Biblia, su norma de fe y conducta; tal fue el valor dado a las Escrituras que a los ministros presbiterianos se les animaba a emprender la tarea de aprender el hebreo y el griego para leerlas en los idiomas originales, griego y hebreo, como parte de su ejercicio hermenéutico ${ }^{29}$.

${ }^{25}$ AIEPM, Libro de actas Primera Convención, Acta 3, Medellín, 22 de julio de 1926, f. 3-4; Juana de Bucana, La Iglesia evangélica en Colombia: una historia (Bogotá: WEC International, 1995), 52-54; Fabio Hernán Carballo, La persecución a los protestantes en Antioquia durante la violencia bipartidista de mediados del siglo XX (Medellín: IDEA, 2013), 40; Francisco Ordóñez, Historia del cristianismo evangélico en Colombia, 105$106,134$.

${ }^{26}$ Javier Augusto Rodríguez Sanín, Hacia una historia del protestantismo en Colombia, 115: «Este periódico jugó un papel importante para el desarrollo de la obra y servía como tribuna en la lucha por algunos derechos que los protestantes reclamaban, como establecimientos de cementerios laicos, matrimonio civil, libertad de expresión principalmente en el sentido religioso, denuncias de persecución religiosa, etc. Sirvía también como órgano informativo del desarrollo de la obra protestantes, no solo de Colombia sino de América Latina y del mundo entero, también de algunas noticias nacionales e internacionales; y principalmente era el vehículo de una cantidad de artículos religiosos: unos de carácter ético en contra de vicios como el tabaco y el alcoholismo e inculcando la honradez, puntualidad, esfuerzo en el trabajo y estudio; y otros de carácter polémico con respecto a las doctrinas católicas».

${ }^{27}$ Diana Luz Ceballos Gómez, «Desde la formación de la República hasta el Radicalismo liberal (1830-1886)», en Historia de Colombia. Todo lo que hay que saber, Luis Enrique Rodríguez Baquero, et al. (Bogotá: Aguilar, Altea, Taurus, Alfaguara, 2011), 206: «De ahí que el papel que desempeñó la prensa en el siglo XIX fuera, sin exagerar, fundamental. La prensa era el medio a través del cual se creaba un vínculo con el mundo y se tenía acceso a una parte importante de la cultura. No solo los acontecimientos políticos y noticiosos pasaban por los periódicos, como sucede con frecuencia en nuestros días, sino que aun la música -en forma de partituras que podían ser interpretadas por aficionados, pues todavía no existía el fonógrafo-, la literatura nacional e internacional e incluso los anuncios de nuevos bienes y servicios llegaban por ese medio. La prensa tenía, asimismo, una misión civilizadora muy acorde con la idea del progreso que regía el comportamiento de los sectores dirigentes de esos años».

${ }^{28}$ Armado Montenegro y Rafael Rivas, Las piezas del rompecabezas. Desigualdad, pobreza y crecimiento (Bogotá: Taurus, 2005), 151-158; Javier Augusto Rodríguez Sanín, Hacia una historia del protestantismo en Colombia, 184-185.

${ }^{29}$ Jaime Jaramillo Uribe, Historia de la pedagogía como historia de la cultura, $2^{\text {a }}$ edición (Bogotá: Centro de Investigación y Educación Cooperativas - CIEC, 1978), 53-54. 


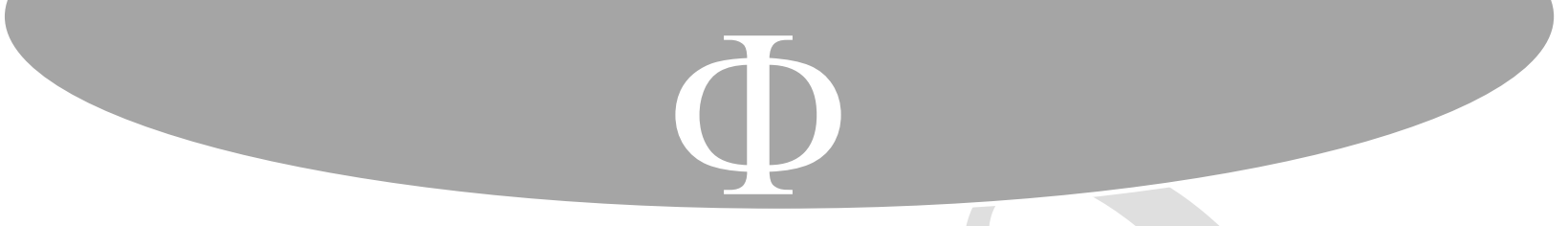

Otra de las principales labores del Rev. Allan fue el reconocimiento del territorio, sus gentes, idiosincrasia, necesidades y oportunidades como estrategia eficaz de establecer un protestantismo contextualizado ${ }^{30}$. Recorrió a lomo de caballo, junto con el Rev. Carlos Chapman de la Unión Misionera, cada rincón del departamento del Tolima, parte de los departamentos del Huila, Cundinamarca, Santander, los alrededores de Barranquilla e incluso algunos lugares de los Llanos Orientales. Esto le permitió en cada pueblo que visitaba entrar en contacto con sus gentes, compartirles la fe protestante y promocionar la lectura de la Biblia $^{31}$.

Se ha afirmado que el fracaso del establecimiento del régimen liberal radical se dio debido a la no correspondencia entre sus convicciones y su manera de actuar, como lo afirma Ricardo Arias: «Si las convicciones más íntimas de los radicales no coinciden con las leyes que ellos mismos promueven, si como ciudadanos no se atreven a romper con los moldes impuestos por la moral católica, que tan ferozmente combaten como políticos, hay que preguntarse, por consiguiente, si la posición del radicalismo en materia religiosa no resulta bastante ambigua y contradictoria» ${ }^{32}$. Caso contrario se da entre las convicciones de los protestantes que coinciden con su manera de actuar, esto marcó el carácter del presbiteriano. La coherencia entre enseñanza, convicciones y vida de los misioneros, aun a precio de persecución y muerte, revistió la empresa misionera de autoridad y promovió la formación de nuevo liderazgo con esas mismas características ${ }^{33}$.

\footnotetext{
${ }^{30}$ Diana Luz Ceballos Gómez, «Desde la formación de la República hasta el Radicalismo liberal (1830-1886)», 199 y 201, la práctica del Rev. Allan no distó mucho del propósito de las nuevas repúblicas en conocer los saberes y las representaciones de sus gobernados: «Una porción del interés por estudiar el territorio y las gentes de un país parte de la premisa de que conocer a quiénes y qué se va a gobernar es una buena manera de legitimar una configuración política determinada. En esta línea se inscriben la elaboración de censos y de estadísticas, de geografías y de mapas, las relaciones de viaje y la creación de museos, bibliotecas y eventos para fomentar determinados tipos de productos culturales. Desde la expedición Botánica del siglo XVIII y durante todo el siglo XIX, este interés por conocer el país se materializó en textos académicos, de crónica y literarios, en relatos de viajeros extranjeros y nacionales, en las instituciones y en el arte. (...) Las geografías, en particular, fueron un elemento clave para el fomento de la integración nacional, ya que buscaron representar a los habitantes de las diferentes regiones como individuos cercanos, identificados con una patria común, unos intereses materiales y unas estrategias de progreso conjuntos. La cartografía, por otra parte, permitía conocer el país, sus pobladores y sus recursos con propósitos prácticos: la transformación del territorio para hallar el camino del progreso; el conocimiento de su espacialidad, con el objeto de realizar una división territorial puesta al servicio de la representación política».

${ }^{31}$ Alexander M. Allan, Recuerdos 1910-1945, 1- 48; Francisco Ordóñez, Historia del cristianismo evangélico en Colombia, 131-154; Juana de Bucana, La Iglesia evangélica en Colombia: una historia, 70-71; F. W. Shillingsburg, La llama que nunca se apaga. Breve historia de la Unión Misionera Evangélica durante sus setenta y cinco años de mantener en alto la llama, 1908-1983 (Cali: Aurora, 1983), 11-16.

${ }^{32}$ Ricardo Arias, El episcopado colombiano: intransigencia y laicidad, 1850 - 2000 (Bogotá: Uniandes, 2003), 43.

${ }^{33}$ Émile Durkheim, «El porvenir de la religión (1914)», 86: «La experiencia nos enseña, en efecto, que cuando los hombres se reúnen, cuando viven una vida común, de esa misma agrupación brotan fuerzas excepcionalmente intensas que los dominan, los exaltan, que conducen su tono vital a un grado que no conocen en la esfera privada. Bajo el efecto del entusiasmo colectivo, son a veces asaltados por un verdadero delirio que los empuja a realizar actos en los que ellos mismos no se reconocen».
} 


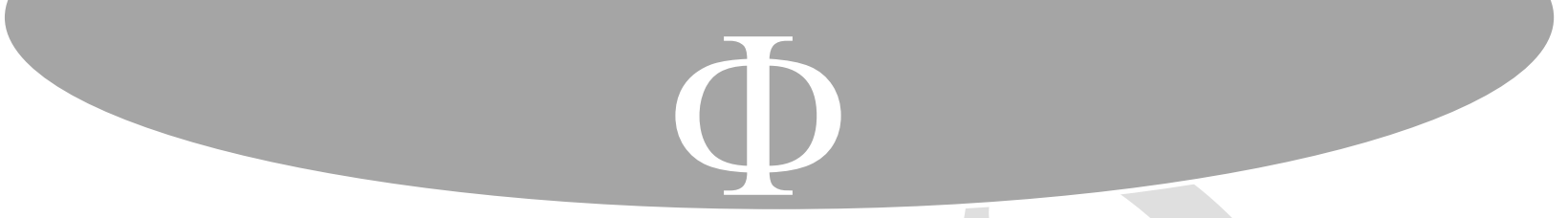

Otra expresión del presbiterianismo, como los describiría Juan Mackay, fueron los «moderados» o «progresistas», entre estos se encontrara el prestigioso misionero, Rev. James Goff, un académico que hizo un estudio monumental para su disertación doctoral sobre la persecución religiosa en Colombia ${ }^{50}$. La Confederación Evangélica de Colombia (CEDEC), actual CEDECOL, debido a la persecución a la Iglesia Protestante en Colombia, lo nombró como miembro de la Comisión de Investigación ${ }^{51}$.

\section{La persecución hacia los protestantes}

La Violencia ${ }^{52}$ es un periodo en la historia de Colombia que afectó de manera directa a la Iglesia Protestante. Los ataques anti-protestantes comenzaron de manera esporádica en 1946 pero el nivel se incrementó en 1948. También se puede afirmar que 1958 fue el año en que terminó, no tanto porque cesara la persecución sino porque al finalizar este año se comenzaron a dar cambios significativos que propiciaron una nueva realidad política en Colombia. En agosto de 1958 llegó a la presidencia el liberal Alberto Lleras Camargo quien brindó garantías y protección a los protestantes. Otro acontecimiento internacional ocurrió en octubre de 1958, fue elegido Angelo Giuseppe Roncalli, Juan XXIII, como Papa. Este Papa trajo una política de fraternidad y conciliación frente a los protestantes. Las nuevas directrices Vaticanas pronto afectaron al clero colombiano, propiciando un cambio de actitud frente a los protestantes ${ }^{53}$.

${ }^{50}$ Javier Voelkel, entrevistado por Luis Eduardo Ramírez.

51 James E. Goff, The Persecution of Protestant Christians in Colombia, 1948-1958 (Cuernavaca: CIDOC, 1968), 1/10; Francisco Ordóñez, Historia del cristianismo evangélico en Colombia, 471-472.

52 Marco Palacios y Frank Stafford, Colombia: país fragmentado, sociedad dividida. Su historia (Bogotá: Norma, 2002), 631-632: «Esta historia empieza con La Violencia, con mayúscula y bastardillas, que dan cuenta de su especialidad, pues así escrito el vocablo se refiere a una serie de procesos provinciales y locales sucedidos en un período que abarca de 1946 a 1964, aunque descargó su mayor fuerza destructiva entre 1948 y 1953 . En estos años se partió en dos el siglo XX colombiano». Ver también el análisis que hace Ricardo Arias Trujillo, Historia de Colombia Contemporánea (1920-2010) (Bogotá: Uniandes 2010), 89: «La Violencia es una denominación vaga, abstracta. Frases repetidas por miles de campesinos, como "la violencia mató mi familia", "la violencia me quitó la tierra", "la violencia me hizo huir del campo", no aludían a nadie en concreto, no se referían a personas que pudiesen ser identificadas; remitían, más bien, a una especie de "fatalidad histórica", similar a un terremoto o a cualquier otra calamidad provocada por la naturaleza. Por la naturaleza, no por los hombres, no por el entorno social. (...) Lograr que la sociedad hablara no de "guerra civil", sino de "la violencia" obedecía, por consiguiente, a los intereses ideológicos de aquellos que, una vez finalizado el conflicto, querían, por una parte, borrar toda huella de su responsabilidad y, en segunda medida, presentar ese triste paréntesis como una disrupción pasajera de una historia no violenta»; Christopher Abel, Política, iglesia y partidos en Colombia: 1886-1953, Trad. Mercedes Herzig y Jorge Alberto Restrepo (Bogotá: FAES, 1987), 152-171; William Beltrán, «El evangelicalismo y el movimiento pentecostal en Colombia en el siglo XX», en Historia del cristianismo en Colombia. Corrientes y diversidad, dir. Ana María Bidegain (Bogotá: Taurus, 2004), 456-468.

${ }^{53}$ James E. Goff, The Persecution of Protestant Christians in Colombia, 1948-1958, 1/10; Rodolfo Ramón de Roux, «La Iglesia colombiana desde 1962», en Historia General de la Iglesia en América Latina, Tomo VII Colombia y Venezuela, coord. Enrique Dussel (Salamanca: Sígueme, 1981), 559-589; Emilio A. Núñez, Teología de la Liberación. Una perspectiva evangélica (San José: Caribe, 1986), 81-82: «De gran importancia es también la enseñanza del Vaticano II tocante a la Iglesia como el Cuerpo de Cristo. (...) pero surge la pregunta en cuanto a cuál es la iglesia, o estructura visible, que expresa la unidad del Cuerpo de Cristo. 


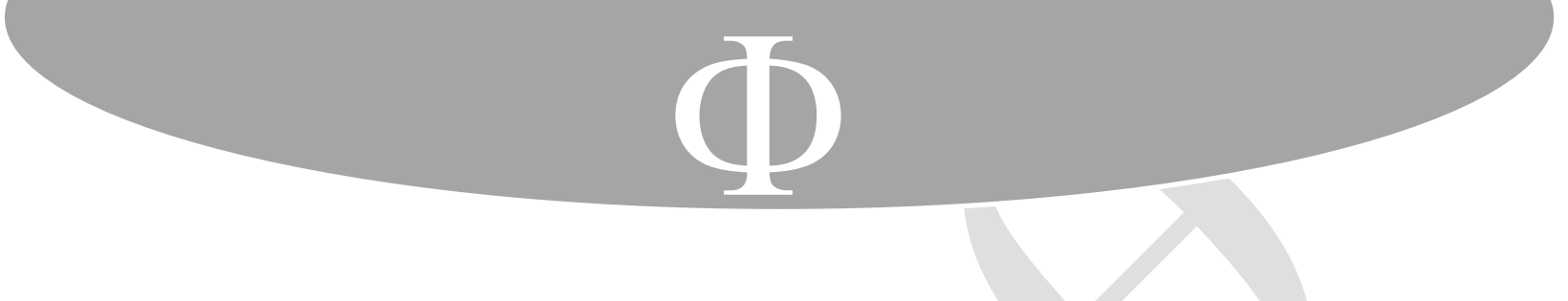

En Colombia el ambiente se había ensombrecido cuando el presidente conservador Laureano Gómez intento hacer una reforma constitucional que pretendía echar para atrás las reformas emprendidas por los liberales y establecer un estado corporativo, fue entonces cuando el bando ospinista y los liberales apoyaron la intervención militar del general Gustavo Rojas Pinilla el 3 de junio de 1953, denominado por Darío Echandía como «golpe de opinión» ${ }^{54}$. La etapa más fuerte de la Violencia se dio en el periodo de los gobiernos conservadores, entre 1946 y 1953 cuando sucedió el golpe de Estado, esta etapa coincide con el incremento de la persecución protestante ${ }^{55}$. Por tal motivo tanto los gobiernos conservadores como la Iglesia Católica afirmaron que cualquier violencia que la Iglesia Protestante hubiera experimentado en este periodo no se debió a una persecución religiosa sino a sus insultos a las creencias más valoradas de los colombianos debido a la predicación imprudente e irrespetuosa de los protestantes, y en especial de la intervención en las luchas políticas, identificándose con los liberales, y a su rebelión contra el gobierno conservador, en resumen según ellos estas fueron las verdaderas causas de la mal denominada persecución contra los protestantes. Algunos Jesuitas se encargaron de dibujar a los protestantes como un movimiento divisorio y antipatriota que llevó de forma natural a una persecución. Para los católicos en Colombia no existió persecución hacia los protestantes ya que en el país no hubo

Tradicionalmente, la respuesta del catolicismo a esta pregunta ha sido que es la Católica Romana. Pero el Vaticano II usa un eufemismo cuando dice: "Esta Iglesia, establecida y organizada en este mundo como una sociedad, subsiste en la Iglesia católica, gobernada por el sucesor de Pedro y por los Obispos en comunión con él". Se ha dicho que el uso de "subsiste" en lugar de "es" representa uno de los cambios más significativos en la eclesiología del catolicismo, puesto que deja "espacio teológico" para otras comunidades eclesiales. El texto conciliar añade que hay la posibilidad de que fuera de la estructura de la Iglesia Católica se encuentren "muchos elementos de santidad y verdad que, como bienes propios de la Iglesia de Cristo, impelen hacia la unidad católica". En otras palabras, todo lo bueno y verdadero que existe fuera del catolicismo pertenece a la Iglesia, cuya expresión plena se da solamente en la comunidad católica romana».

${ }^{54}$ Rodolfo Ramón de Roux, «La Iglesia colombiana desde 1962», 532; Germán Guzmán, Orlando Fals Borda y Eduardo Umaña Luna, La violencia en Colombia. Estudio de un proceso social, Tomo I (Bogotá: Universidad Nacional de Colombia, 1962), 45.125; Amparo Murillo Posada, «La modernización y las violencias (19301937)», en Historia de Colombia. Todo lo que hay que saber, Luis Enrique Rodríguez Baquero, et al. (Bogotá: Aguilar, Altea, Taurus, Alfaguara, 2011), 292-306; Ricardo Arias, El episcopado colombiano: intransigencia y laicidad, 1850 - 2000, 139-147; Helwar Figueroa y Carlos Tuta, «El corporativismo de mediados del siglo XX en Colombia. Una propuesta de derechas», Grafía 3 (2005): 31-43; Salvador Giner y Manuel Pérez Yruela, La sociedad corporativa (Madrid: Centro de Investigaciones Sociológicas, 1979), 98-110; Thoma J. Williford, Laureano Gómez y los masones 1936-1942 (Bogotá: Planeta, 2005), 73-153.

${ }^{55}$ Ricardo Arias Trujillo, Historia de Colombia Contemporánea (1920-2010), 91: «Bajo los conservadores, se desató la persecución contra los protestantes. Los "herejes" eran acusados, naturalmente, de negar la supremacía del catolicismo y de difundir sus mentiras en el seno de una población mayoritariamente católica. A sus pecados religiosos, se agregaban sus errores políticos, que se manifestaban en sus simpatías por el Partido Liberal, el cual en ocasiones, había mostrado cierto interés por la libertad religiosa. En medio del fragor de la Violencia, los simpatizantes del protestantismo fueron hostigados y varios de sus templos sufrieron actos vandálicos. La Iglesia católica se defendió de las acusaciones que, junto con los conservadores, la señalaban como instigadora de los ataques contra la comunidad protestante, alegando que tales hostigamientos no tenían relación alguna con cuestiones religiosas. Los casos en que los protestantes habían sido víctimas de la violencia, si es que los había, se inscribían en el conflicto bipartidista: es decir, como los "herejes" apoyaban a los liberales, era apenas lógico que pudieran verse afectados en el marco de las luchas bipartidistas». 


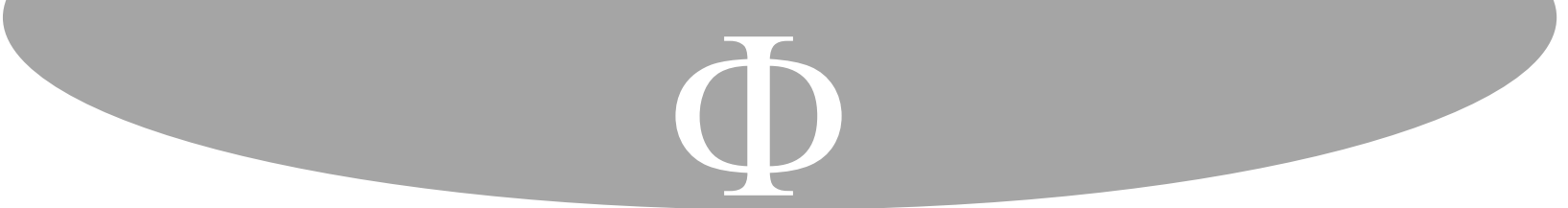

Liberal Protestante, cuyo objetivo era una reelaboración del pensamiento cristiano a la luz de la cultura, la filosofía y la ciencia moderna, y un redescubrir el verdadero sentido del evangelio, acorde al pensamiento moderno, sin la mediación de la tradición dogmática. En reacción a este movimiento «modernista» surgieron dos movimientos, el primero fue el fundamentalismo, con el trasfondo de la tradición ortodoxa protestante y el sentimiento antimodernista, que consideró la propuesta liberal como una religión completamente diferente de la cristiana. Uno de sus representantes fue el presbiteriano J. Gresham Machen, quién puso énfasis en la doctrina de la inerrancia y verdad literal de la Biblia. El segundo movimiento, vino de Europa llamado «neo-ortodoxia» y representado por los suizos Karl Barth y Emil Brunner, y el estadounidense H. Richard Niebuhr, cuya teología fue una de las más influyentes en el siglo $\mathrm{XX}^{73}$. En América Latina fue el misionero presbiteriano Juan Mackay quién inspiro el estudio del filósofo español Miguel de Unamuno y la teología de Karl Barth ${ }^{74}$. Por el lado católico, el intento de traer a la Iglesia al mundo moderno, se dio a través de dos eventos, el primero y que más impacto tendría en la Iglesia Cristiana Universal fue el Concilio Vaticano II, el segundo que influenció la pastoral en América Latina fue Conferencia Episcopal Latinoamericana (CELAM II) celebrada en Medellín en $1968^{75}$. Estos también tuvieron su contra parte en algunos prelados, el pontificado de Pablo VI y en especial en el pontificado de Juan Pablo II $^{76}$.

La herencia teológica que se traía del siglo XIX impactó la labor misionera presbiteriana, ahora en el siglo XX, las nuevas tendencias enriquecerían el quehacer teológico de la Iglesia Presbiteriana, con la participación activa de los colombianos. En el plano político y cultural, América Latina estaba siendo influenciada por las tensiones geopolíticas de la Guerra Fría, el gobierno comunista de Fidel Castro en Cuba (1959), las políticas estadounidenses del presidente Kennedy con el programa «Alianza para el Progreso» (1961), las protestas contra la guerra del Vietnam (1965), la conformación de las guerrillas

\footnotetext{
${ }^{73}$ Roger E. Olson, The Story of Christian Theology, 533-589.

${ }^{74}$ James H. Moorhead, «The Ecumenical Vision of John A. Mackay», Theology Today 3, Vol. 71 (2014): 276291; John Sinclair, «Un perfil de John A. Mackay: Aquel escocés con alma Latina», Vida y Pensamiento 2, Vol. 30 (2010): 29-47; Guidoberto Mahecha, «John Alexander Mackay 1889-1983», Vida y Pensamiento 2 , Vol. 30 (2010): 7-28; Benjamín F. Gutiérrez, «La influencia de John Mackay en las iglesias de América Latina y el Caribe. Entrevistas con personas que lo conocieron personalmente», Vida y Pensamiento 2, Vol. 30 (2010): 49-74; John Alexander Mackay, «Bonn 1930 - and after: A Lyrical Tribute to Karl Barth», Theology Today 3, Vol. 13 (1956): 287-294; John Alexander Mackay, «On the Road: Twenty-Fifth Article in the Series How My Mind Has Changed in This Decade», The Christian Century 28, Vol. 56 (1939): 873-875; Karla Ann Koll, «The Theology of John A. Mackay as Preparatio Liberationis», Theology Today 2, Vol. 73 (2016): 105-116.

${ }^{75}$ Concilio Vaticano II, Constitución pastoral Gaudium et Spes, sobre la Iglesia en el mundo moderno, $4^{\mathrm{a}}$ edición (Bogotá: Ediciones Paulinas, 1970), 147-246; Concilio Vaticano II, Constitución Sacrosanctum Concilium, Sobre la sagrada Liturgia, 4a edición (Bogotá: Ediciones Paulinas, 1970), 111-146. Concilio Vaticano II, Declaración Dignitatis Humanae, Sobre la libertad religiosa, 4ª edición (Bogotá: Ediciones Paulinas, 1970), 470-483; Justo L. González, Historia del cristianismo. Desde la Reforma hasta la era inconclusa, 517-519; Victorino Pérez Prieto, «Los orígenes de la Teología de la Liberación en Colombia: Richard Shaull, Camilo Torres, Rafael Ávila, "Golconda", sacerdotes para América Latina, cristianos por el socialismo y comunidades eclesiales de base», Cuestiones Teológicas 99, Vol. 43 (2016): 80-81. Ricardo Arias, El episcopado colombiano: intransigencia y laicidad, 1850 - 2000, 191-245.

76 Justo L. González, Historia del cristianismo. Desde la Reforma hasta la era inconclusa, 517-520.
} 


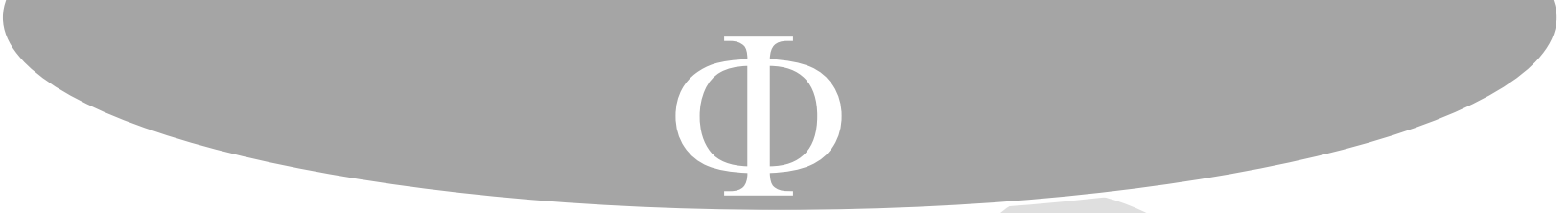

que «la sociología debe estar comprometida con la acción social» ${ }^{94}$; uno de los aportes de Fals Borda y de La Rosca fue desarrollar la metodología Investigación-Acción Participativa (IAP), «no solo como técnica de investigación sino como una estrategia de cambio social» ${ }^{95}$.

El trabajo de Fals Borda demuestra un profundo conocimiento y comprensión de la realidad social lo cual le permitió hacer propuestas innovadoras. En su investigación predominó su cercanía al campesinado y su compromiso por cambiar sus realidades sociales como lo proponía la IAP; en especial cabe resaltar su trabajo con las asociaciones de campesinos de Córdoba bajo la Fundación Rosca de Investigación y Acción Social ${ }^{96}$.

La Iglesia Presbiteriana en la década de los 60 y 70, igual que pasa en las iglesias más antiguas, mostró una tendencia al formalismo, a una pérdida del entusiasmo y de fervor evangelístico, realidad propia de la primera generación de cristianos. Las nuevas generaciones crearon una cultura o subcultura evangélica nominal. El gran desafío de los líderes fue como mantener el fervor evangelístico en los hijos y los nietos de la primera generación de convertidos. El nominalismo es una tendencia natural que suele darse en las iglesias antiguas, sucedió en la Iglesia Católica, en la Iglesia Presbiteriana, y podrá suceder con las iglesias pentecostales o con muchas iglesias nuevas ${ }^{97}$.

Las realidades que tuvieron que enfrentar a lo largo del siglo XX los pastores, forjaron el talante del liderazgo presbiteriano; ejemplo son los ministros: Gustavo Villa, Aristóbulo Porras, Aristomeno Porras, Juan Rocha, Rosendo Ayala, Vicente Rodríguez, Juan Pino, Gilberto Vargas, Álvaro Peña, Roberto Argel, Arcesio Cruz, Hernán Mendoza, Dimas

\footnotetext{
${ }^{94}$ Gonzalo Castillo Cárdenas e Isay Pérez Benavides, La influencia religiosa en la conciencia social de Orlando Fals Borda, 16; Victorino Pérez Prieto, «Los orígenes de la Teología de la Liberación en Colombia: Richard Shaull, Camilo Torres, Rafael Ávila, "Golconda", sacerdotes para América Latina, cristianos por el socialismo y comunidades eclesiales de base», 86; Gonzalo Cataño, «Orlando Fals Borda, Sociólogo del compromiso», Espacio Abierto 4, Vol. 17 (2008): 552.

${ }^{95}$ Gonzalo Castillo Cárdenas e Isay Pérez Benavides, La influencia religiosa en la conciencia social de Orlando Fals Borda, 18-19; Víctor Negrete, «A la memoria del maestro Orlando Fals Borda: bases y desarrollo de la Investigación-Acción Participativa en Córdoba (Colombia)», International Journal of Psychological Research 2, Vol. 1 (2008): 86.

${ }^{96}$ Víctor Negrete, «A la memoria del maestro Orlando Fals Borda: bases y desarrollo de la Investigación-Acción Participativa en Córdoba (Colombia)», 85-97; Milcíades Vizcaíno G., «De la realidad a la utopía: una incursión por la vida y obra de Orlando Fals Borda», Espacio Abierto 4, Vol. 17 (2008): 573-575; Gonzalo Castillo Cárdenas e Isay Pérez Benavides, La influencia religiosa en la conciencia social de Orlando Fals Borda, 21; Gonzalo Cataño, «Orlando Fals Borda, Sociólogo del compromiso», 561; Lola Cendales, Fernando Torres y Alfonso Torres, «One sows the seed, but it has its own dynamics: an interview with Orlando Fals Borda», 2425.

${ }^{97}$ Ernst Troeltsch, The Social Teaching of the Christian Churches, Vol. 1, Trad. Olive Wyon (Londres: George Allen and Unwin Ltd, 1949), 331-334, afirma con respecto al tema, que iglesias que han surgido de movimientos de conversión se caracterizan por la pérdida de su fervor original y de un profundo compromiso con sus creencias, estas comunidades se han adaptado a las estructuras sociales existentes hasta el punto determinar y estabilizar el orden social, son inclusivas y han desarrollado una estructura eclesial y sacramental bien definida; sus adeptos provienen de niveles sociales más altos, muchas veces por pertenecer a la segunda generación de los miembros de las sectas. Lo mismo se evidenció en Colombia como lo narró Javier Voelkel, entrevistado por Luis Eduardo Ramírez.
} 


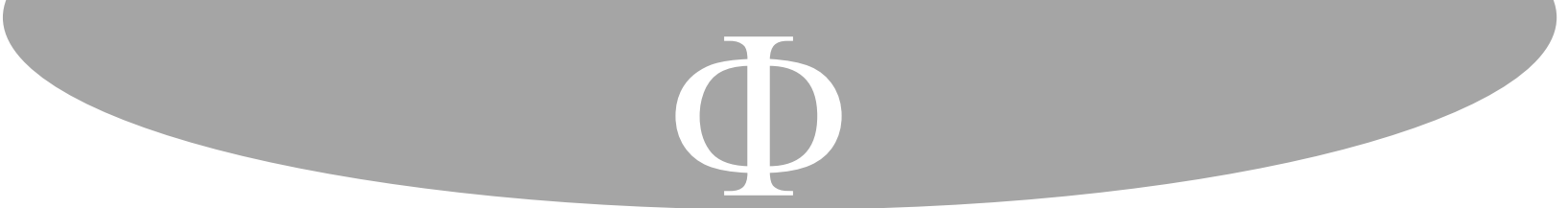

Cañón, Edilberto Daza, Misael Acero, Germán Ezequiel Suárez, Jaime Ortiz Hurtado, egresado del Seminario Presbiteriano de Campinas Brasil, rector del Seminario Bíblico de Colombia, Constituyente y Senador de la República; estos ministros son fieles representantes del ala moderada. Ministros y ancianos como Alfonso Lloreda, Javier Zarate, Eugenio Illidge, Augusto Libreros, Gonzalo Castillo, Javier Rodríguez, David Illidge, Derney Ramos, Milton Mejía, Milciades Púa, Elis Barraza, Luis Fernando San Miguel, Isay Pérez, son representantes del ala progresista ${ }^{98}$. Ambas expresiones de liderazgo presbiteriano representan al ministro presbiteriano, ambas complementan el talante presbiteriano.

\section{El talante de la mujer presbiteriana}

La Iglesia Presbiteriana colombiana adolece de una historia, escrita desde la óptica de las mujeres, sobre el papel que ellas desempeñaron en el desarrollo de la Iglesia ${ }^{99}$. En esta sección no se pretende abordar el tema de manera exhaustiva pero sí se quiere presentar una visión panorámica como tributo al liderazgo de las mujeres que han salido del seno de la Iglesia en el transcurso de su historia en Colombia.

La Iglesia Presbiteriana estadounidense en el siglo XIX ya había enviado mujeres como misioneras en la colonización del Oeste de los Estados Unidos ${ }^{100}$. Esta tradición de mujeres involucradas en las misiones se evidenció en las misioneras que llegaron a Colombia, muchas de ellas de clase media y con formación universitaria ${ }^{101}$, esto contrastaba con mucha de la realidad colombiana, a excepción de algunas religiosas, pues en el siglo XIX las mujeres fueron uno de los sectores excluidos de la sociedad, esta realidad en el país no cambió en las primeras dos décadas del siglo $\mathrm{XX}^{102}$. El Congreso Misionero de Panamá de 1916 muestra una fuerte presencia femenina en el desarrollo de las misiones en el continente:

En 1916 existían 32 Juntas Misioneras Femeninas, tanto independientes o auxiliares en Estados Unidos, Canadá, Gran Bretaña y Alemania, que enviaban y

\footnotetext{
98 Javier Voelkel, entrevistado por Luis Eduardo Ramírez: «Algunos de estos pastores fueron influenciados por sus estudios en el exterior en seminarios como el de Matanzas en Cuba, el de Costa Rica, el de Campinas en Brasil y otros en EEUU, instituciones abiertas e influenciadas por lo que llegó a ser la Teología de la Liberación»; Theo Donner, Posmodernidad y fe: una cosmovisión cristiana para un mundo fragmentado, 11. ${ }^{99}$ Diana Luz Ceballos Gómez, «Desde la formación de la República hasta el Radicalismo liberal (1830-1886)», 213: «Toda construcción de la memoria, como se sabe, individual o colectiva, se hace de manera sesgada. Qué se olvida, qué se recuerda y por qué se olvida y se recuerda en una sociedad es lo que explica, en una buena proporción, su historia narrada».

100 PCUSA, «Who Are We Presbyterians»: «en el siglo XIX a medida que la nación se extendía hacia el Oeste, los misioneros presbiterianos encabezaban el proceso, entre ellos se encontraban Narcissa Prentiss Whitman y Eliza Hart Spalding, quienes en 1835 fueran las primeras mujeres blancas que cruzaron la división continental sirviendo en los pueblos de nativos norteamericanos en el Oeste». Ver también Presbyterian Historical Society, «Eliza Hart Spalding Letters», consultada en agosto 7, 2019, https://www.history.pcusa.org/eliza-hart-spaldingletters. The Historical Society Prattsburgh, «Narcissa Prentiss Whitman», consultada en agosto 7, 2019, http://historyofprattsburgh.com/2011/02/narcissa-prentiss-whitman/.

101 Jean Pierre Bastian, Protestantismo y modernidad latinoamericana, 112.

102 Diana Luz Ceballos Gómez, «Desde la formación de la República hasta el Radicalismo liberal (1830-1886)», 213-214; Ricardo Arias, El episcopado colombiano: intransigencia y laicidad, 1850 - 2000, 86-95.
} 


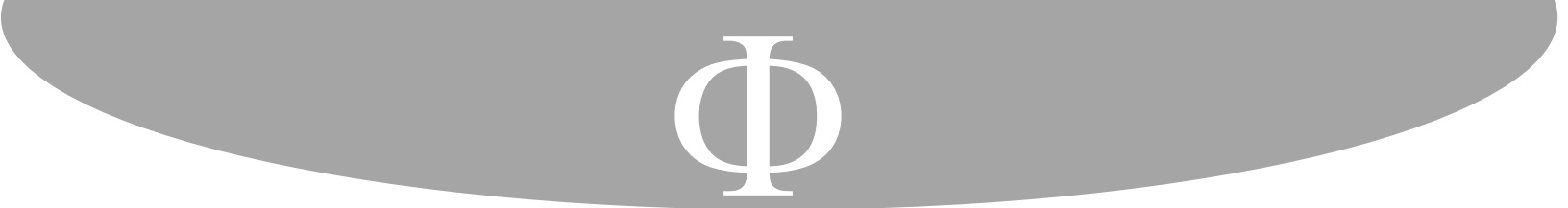

vieron que las promesas no se cumplían, o se cumplían apenas en parte, tornaron nuevamente al Colegio Americano» ${ }^{114}$.

En los años 30 del siglo XX, llegó a Girardot la educadora Francisca Hitchcok quien fundó la Escuela Normal que sirvió para la formación de las maestras de los colegios protestantes. En 1953 llegaron a la ciudad los esposos Emery, el trabajo de doña Elena de Emery fue invaluable para la Iglesia y la ciudad ${ }^{115}$. Con la llegada de los esposos Porras la Iglesia y el Colegio se fortalecieron, la Rvda. Rosina de Porras sirvió incasablemente en la obra evangelística, educativa y social. Doña Rosina y su esposo fundaron un albergue para que niños y niñas del campo pudieran venir a estudiar a la ciudad, este fue dirigido por la Rvda. Rosina de Porras y apoyado durante 12 años por la Sociedad de Damas de la Iglesia Presbiteriana de Girardot. Luego cuando se trasladaron a Ibagué fundaron un nuevo albergue con un programa similar para niños y niñas internos ${ }^{116}$.

La obra de predicación, de acción educativa y recreativa se incrementó; el evangelio cambiaba y renovaba vidas; el colegio que nunca se ha apartado de la enseñanza de las Sagradas Escrituras, aportaba becas y descuentos; la Iglesia con los aportes foráneos de Ayuda Estudiantil contribuía a elevar el nivel social y económico de las familias, pues los rigores de la violencia político religiosa, trajo creyentes de Iglesias rurales en situaciones críticas. Y así se edificó el Albergue Elena de Emery, para personas de la tercera edad, que con módicas sumas de familiares, eran atendidas con comida, medicina y techo; luego fue el internado para estudiantes de iglesias de pueblos vecinos, quienes por carencia de Centros Educativos en sus lugares, venían y estudiaban en colegios oficiales y el SENA. Todo este trabajo estaba a cargo de un grupo administrativo, cuya directora era la señora Rosina de Porras ${ }^{117}$.

Otra mujer admirable por su ministerio fue la Rvda. Lilia Benítez de Ramírez, egresada del Seminario Bíblico de Costa Rica, quien pastoreó junto a su esposo, el Rev. Noel Ramírez, iglesias en varias regiones de Colombia. A la muerte de su esposo ella continuo en el pastorado en Barranquilla, dos de sus hijos siguieron los pasos de sus padres en el pastorado Uriel y Lilia María ${ }^{118}$. Los aportes a la formación de músicos y al desarrollo de

\footnotetext{
${ }^{114}$ Francisco Ordóñez, Historia del cristianismo evangélico en Colombia, 102-104; The Fifty-Ninth Annual Report of the Board of Foreign Missions of the Presbyterian Church of the United States of America (New York: Presbyterian Church the USA, 1896), 232-233.

115 Carmen de Gahona, «Semblanza Iglesia Presbiteriana de Girardot. Monumento del primer centenario de la obra en Colombia», 58-59: «La Iglesia luego del pastorado, administración y apostolado del Revdo. Emery y su esposa doña Elena, quienes amaron a esta ciudad colaborando en actividades cívicas: Casa de la Cultura, la Liga contra el Cáncer, repito, siguieron su labor de misioneros evangelistas».

116 Germán Ezequiel Suárez Núñez, dir., Primera Iglesia Presbiteriana de Bogotá, Príncipe de Paz 150 años, $164-165$.

${ }^{117}$ Carmen de Gahona, «Semblanza Iglesia Presbiteriana de Girardot. Monumento del primer centenario de la obra en Colombia», 60.

118 Germán Ezequiel Suárez Núñez, dir., Primera Iglesia Presbiteriana de Bogotá, Príncipe de Paz 150 años, 103.
} 


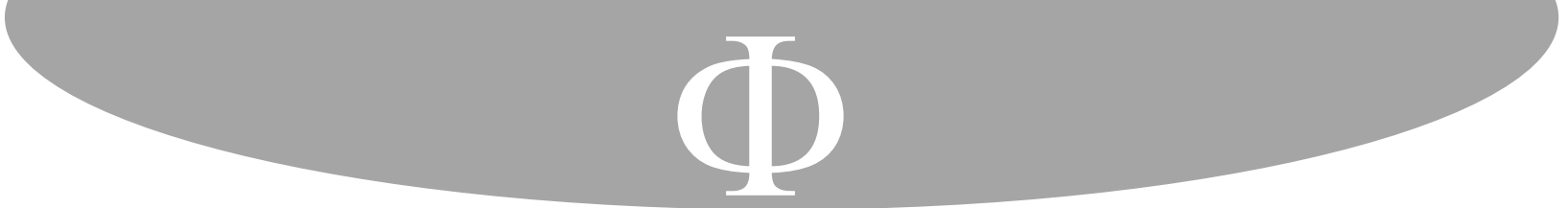

ministerios musicales en las iglesias tuvieron la influencia de la señora Eleonora de Lazear ${ }^{119}$ y la señora Pulina Loew, fundadora junto con su esposo el Rev. Alvin Schutmaat de la Escuela de Música Presbiteriana en Bogotá ${ }^{120}$. La Rvda. Alicia Winter, una mujer brillante, abogada y teóloga, muy sensible a la pobreza y a las necesidades de los campesinos y a la justicia social, profesora de Antiguo Testamento quien fue la primera mujer que ejerció la rectoría del Seminario Presbiteriano ${ }^{121}$. Cabe rendir tributo a la labor de la señora Carmen Leal de Gahona, egresada de la Normal Presbiteriana, mujer consagrada al trabajo del Colegio Americano de Girardot, en especial su dedicación a la jornada nocturna para adultos y a la población marginada de la ciudad ${ }^{122}$.

Se podría seguir listando los nombres y aportes de mujeres en el ministerio pastoral, educativo, administrativo y social en la Iglesia, que evidenciaría el talante de la mujer presbiteriana: Margarita Allan; Isabel Gutiérrez de Urdaneta y Martha Raquel Niño, moderadoras del Sínodo; Alba Arrieta, rectora del Seminario Presbiteriano; Almeida de Vega, Ethel Durier Benítez, Sara Baltodano de Mahecha, Amparo Galindo, Carmen Rivero, Sonia Betancur, Carola de Peña, Zenobia de Daza, María Borda, Priscila Atehortúa, Ruth Aldana, Adelaida Jiménez, Gloria Ulloa, Vilma Yanez, Magally de La Parra, Sara Vanegas y la Rvda. Cecilia Romero, discípula de la Rvda. Rosina Benítez de Porras y egresada del Seminario Bíblico de Colombia, quién ha servido por años a la educación de jóvenes en el Colegio Americano de Girardot y apoyado las iglesias del Presbiterio del Sur.

\section{Colombia país de regiones}

El análisis sobre la urbanización del país que hizo el Rev. Alexander M. Allan fue acertado, y probó el éxito de su estrategia evangelística y educativa. La estrategia consistió en hacer un trabajo fuerte entre las clases humildes del campo, para que luego, cuando estas poblaciones migraran a las ciudades pudieran tener una adaptación rápida y se incorporaran a las iglesias en las ciudades ${ }^{123}$.

Como lo afirma Fernán González, desde mediados del siglo XVIII, se evidenció la dificultad de la movilidad social en la rígida estructura social colonial. La movilidad se lograba por la migración a las ciudades o por la colonización de las tierras calientes; precisamente fueron estas zonas donde la Iglesia Católica no tuvo una presencia activa ${ }^{124}$. En el siglo XIX las familias tuvieron un proceso de aculturación a estas zonas de la periferia sin la presencia del Estado ni de la Iglesia Católica, generando una serie de problemas de toda

\footnotetext{
119 Jorge E. Corzo, «Apreciaciones de un luterano sobre la Iglesia Presbiteriana», en Germán Ezequiel Suárez Núñez, dir., Primera Iglesia Presbiteriana de Bogotá, Príncipe de Paz 150 años, 126.

${ }^{120}$ Germán Ezequiel Suárez Núñez, dir., Primera Iglesia Presbiteriana de Bogotá, Príncipe de Paz 150 años, 82-86.

121 Javier Voelkel, entrevistado por Luis Eduardo Ramírez; Doris Ramos, entrevistada por Luis Eduardo Ramírez, Medellín, junio11 de 2019.

${ }^{122}$ Liberato J. Vega, Perfíl de luces: un tributo a Colombia, 29-30.

123 Alexander M. Allan, Recuerdos 1910-1945, v.

${ }^{124}$ Fernán E. González González, Poderes enfrentados. Iglesia y estado en Colombia, 113-118.
} 


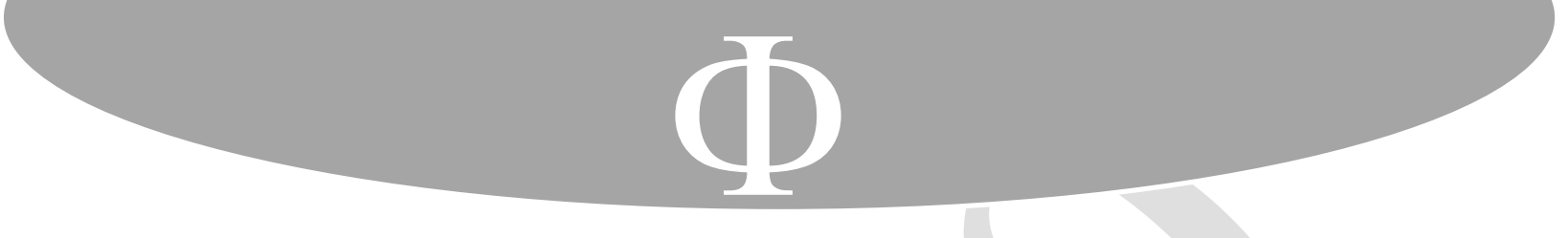

autoritarismo, exclusión, etc.» ${ }^{131}$. Su meta fue la formación de un individuo acorde con el mundo moderno ${ }^{132}$. Como diría Burckhardt «y al lado de esto, se yergue, con pleno poder, lo subjetivo: el hombre se convierte en individuo espiritual y como tal se reconoce» ${ }^{133}$. Un ser humano complejo y pensante que había sido forjado en la idiosincrasia de su región. Esa expresión regional también estará presente en el carácter y la identidad del ser presbiteriano.

Para la formación del ser humano con el talante presbiteriano, fue necesario el trabajo de la Iglesia misionera, que se ha esforzado por hacerse presente en todos los lugares, momentos y esferas de la vida llevando el mensaje transformador de Jesucristo ${ }^{134}$.

\section{Consideraciones finales}

Desde su llagada a Colombia en 1856, la Iglesia Presbiteriana forjó su propia identidad influenciada por las diferentes expresiones exógenas del presbiterianismo que trajeron los misioneros en combinación con los factores endógenos propios de la realidad de colombiana en sus expresiones regionales ${ }^{135}$. Esta combinación ha sido y sigue siendo un factor dinámico en la formación de la identidad presbiteriana.

La Iglesia Presbiteriana a nivel mundial tiene unos rasgos característicos que le dan su propia identidad, tanto por su teología, su sistema de gobierno, su cosmovisión, su praxis

\footnotetext{
${ }^{131}$ Ricardo Arias, El episcopado colombiano: intransigencia y laicidad, 1850 - 2000, 115; Jean Pierre Bastian, Protestantismo y modernidad latinoamericana, 124-125; William Mauricio Beltrán Cely, «Pluralización religiosa y cambio social en Colombia», Theologica Xaveriana 175 (2013): 61-62: «En suma, la modernización, la secularización y la urbanización de la sociedad colombiana trajeron consigo un proceso de apertura al mundo que permitió a la población entrar en contacto con ideas y actores que la Iglesia Católica no está en capacidad de regular ni controlar, y que llegan incluso a cuestionar su legitimidad y liderazgo religioso. Ello se ha traducido en un progresivo debilitamiento de la influencia de la Iglesia Católica sobre la sociedad, y en el deterioro de sus mecanismos de reproducción transgeneracional».

132 Ricardo Arias, El episcopado colombiano: intransigencia y laicidad, 1850 - 2000, 57-58: «(...) señala tres características esenciales de ese espíritu moderno, todas ellas relacionadas con la "nueva conciencia que el hombre ha tomado de sí mismo y de sus potencialidades". En primer lugar, el advenimiento del individuo, que muy rápidamente se convierte en el dueño de su propia conducta y de su capacidad de juzgar; se trata de una verdadera revolución que le permite decir "en conciencia y según su razón lo que debe pensar, hacer y creer". Como resultado de esa evolución, la conciencia, "en lugar de responder a la voz de una autoridad exterior que le dicta una serie de normas, somete estas últimas a su propio tribunal". En segundo lugar, la separación que se establece entre lo privado y lo público hace de la religión un asunto puramente personal. Finalmente, el "principio de integración orgánico" sobre el cual reposaban las sociedades tradicionales se derrumba y en su lugar aparece un "principio de estricta separación, que progresivamente conduce a diversas separaciones; entre los tres poderes (...); entre las esferas de lo público y de lo privado, entre el Estado y las Iglesias (...), entre las leyes de la economía y las leyes de la moral, entre la razón y la fe, entre la ciencia y la creencia, etc. El principio de laicidad es el corolario de todo este proceso". El control que hasta entonces ejercía la Iglesia sobre el mundo se ve cuestionado».

133 Jacob Burckhardt, La cultura del renacimiento en Italia, 105.

134 Juan A. Mackay, El sentido presbiteriano de la vida: lo que significa vivir y adorar como presbiteriano, 161-162.

${ }^{135}$ Ramírez Suárez, Luis Eduardo, «Una historia de la Iglesia Presbiteriana en Colombia, 1993-2013», Ventana Teológica Año 4 (2013): 22-23. https://www.unisbc.edu.co/wp-content/uploads/2020/05/VT05-DIC2013.pdf.
} 


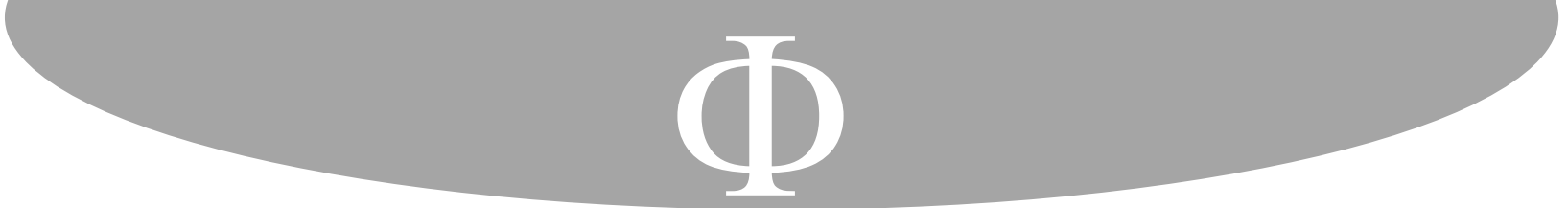

acontecimientos marcaron las relaciones entre católicos y protestantes: el primero fue el Concilio Vaticano II que cambió radicalmente el panorama y la relación de la Iglesia Católica con el mundo protestante. El segundo, la Conferencia Episcopal de Medellín 1968 que marcó la pastoral social de la Iglesia y su opción por los pobres, y fomentó el diálogo entre estas vertientes del cristianismo. A su vez, ambos acontecimientos fueron propicios para el desarrollo de la Teología de la Liberación, que tuvo gran influencia sobre el ala progresista de la Iglesia Presbiterana.

La regionalización no fue una deficiencia sino una fortaleza para la Iglesia Presbiteriana colombiana, enriqueció su expresión cultica y su quehacer teológico, eclesial y pastoral. La Iglesia Presbiteriana es un fiel reflejo de la diversidad del pueblo colombiano y la asociación de una variedad de expresiones y matices del presbiterianismo mundial; por lo tanto, la praxis de esta Iglesia la obliga y compromete a vivir el mensaje de unidad del Evangelio en medio de la diversidad.

La teología presbiteriana propugnó por un ser libre pensador sometido a la Biblia como una única norma de fe y conducta. Creó un ser humano con una experiencia profunda de conversión y de convicciones que le llevó a cambios radicales en sus prácticas, costumbres, valores, prejuicios, ceremonias, relaciones, es decir, cambios en sus imaginarios y representaciones que le llevaron a reconstruir y reinterpretar su realidad ${ }^{141}$, y a forjar su propia identidad como Iglesia Presbiteriana de Colombia.

\section{Bibliografía}

Abel, Christopher. Politica, iglesia y partidos en Colombia: 1886-1953. Traducido por Mercedes Herzig y Jorge Alberto Restrepo. Bogotá: FAES, 1987.

Adams, Elizabeth T. «Divided Nation, Divided Church: The Presbyterian Schism, 18371838». Historian 4, Vol. 54 (1992): 683-696.

AIEPM, Libro de actas Primera Convención, Acta 3, Medellín, 22 de julio de 1926, f. 3-4. Allan, Alexander M. Recuerdos 1910-1945. Medellín: Unión, S.f.

Amestoy, Norman Rubén. «Las mujeres en el protestantismo rioplatense 1870-1930», $\begin{array}{llllll}\text { Franciscanum, } & \text { Vol. } & \text { LIV, } & \text { No. } & 157 & \text { (2012): }\end{array}$ https://revistas.usb.edu.co/index.php/Franciscanum/article/view/839.

Arboleda Mora, Carlos. Pluralismo, tolerancia y religión en Colombia. Medellín: UPB, 2011.

Archivo Orlando Fals Borda (AOFB), Iglesia Evangélica. Sínodo de la Iglesia Presbiteriana en Colombia, Montería, Biblioteca del Banco de la República, Centro de Documentación Regional de Montería, Archivo Orlando Fals Borda, Caja 13, Carpeta 06, Fol. 4129-4137. Arias Trujillo, Ricardo. Historia de Colombia Contemporánea (1920-2010). Bogotá: Uniandes 2010.

Arias, Ricardo. El episcopado colombiano: intransigencia y laicidad, 1850 - 2000. Bogotá:

141 Diana Luz Ceballos Gómez Ed., Prácticas, territorios y representaciones en Colombia 1849-1960 (Medellín: Universidad Nacional de Colombia, 2009), 23-28. 
Uniandes, 2003.

Asselt, Willem J. Van. «Protestant Scholasticism: Some Methodological Consideration in the Study of Its Development». Nederlands Archief Voor Kerkgeschiedenis 3, Vol. 81 (2001): 265-274.

Bastian, Jean Pierre. Protestantismo y modernidad latinoamericana. Historia de unas minorías religiosas activas en América Latina. México, D.F.: Fondo de Cultura Económica, 1994.

Bazcko, Bronislaw. Los imaginarios sociales. Buenos Aires: Editorial Nueva Visión, 1991.

Beltrán Cely, William Mauricio. «Del porqué los Pentecostalismos no son Protestantismos». En Creer y poder hoy, memorias de la cátedra Manuel Ancízar, 469-485. Bogotá: Universidad Nacional de Colombia, 2007.

Beltrán, William. «El evangelicalismo y el movimiento pentecostal en Colombia en el siglo XX». En Historia del cristianismo en Colombia. Corrientes y diversidad. Dirigido por Ana María Bidegain, 451-480. Bogotá: Taurus, 2004.

Beltrán Cely, William Mauricio. «Pluralización religiosa y cambio social en Colombia», Theologica Xaveriana 175 (2013): 61-62.

Bosch, Aurora. Historia de Estados Unidos, 1776-1945. Barcelona: Crítica, 2010.

Bucana, Juana de. La Iglesia evangélica en Colombia: una historia. Bogotá: WEC International, 1995.

Builes, Miguel Ángel. Cartas pastorales. Bogotá: Empresa Nacional de Publicaciones, 1957.

Builes, Miguel Ángel. El protestantismo: su historia y sus errores. Gravísima amenaza para la soberanía de los pueblos latinoamericanos. Santa Rosa de Osos: Tipografía Comercial Medellín, 1952.

Burckhardt, Jacob. La cultura del renacimiento en Italia. Traducido por Ramón de la Serna y Espina. Madrid: EDAF, 1982.

Cabrera Becerra, Gabriel. Los poderes en la frontera. Misiones católicas y protestantes, y Estados en el Vaupés colombo-brasileño, 1923-1989. Medellín: Universidad Nacional de Colombia, 2015.

Cabrera, Gabriel. Las Nuevas Tribus y los indígenas de la Amazonia: historia de una presencia protestante. Bogotá: Litocamargo Ltda, 2007.

Carballo, Fabio Hernán, «Discurso antiprotestante en Miguel Ángel Builes», Revista Grafía, Vol. 14, No. 1 (2017): 9-22.

Carballo, Fabio Hernán. La persecución a los protestantes en Antioquia durante la violencia bipartidista de mediados del siglo XX. Medellín: IDEA, 2013.

Castillo Cárdenas, Gonzalo e Isay Pérez Benavides. La influencia religiosa en la conciencia social de Orlando Fals Borda. Barranquilla: Corporación Universitaria Reformada, 2010.

Cataño, Gonzalo. «Orlando Fals Borda, Sociólogo del compromiso». Espacio Abierto 4, Vol. 17 (2008): 549-567.

Ceballos Gómez, Diana Luz. «Desde la formación de la República hasta el Radicalismo liberal (1830-1886)». En Luis Enrique Rodríguez Baquero, et al. Historia de Colombia. Todo lo que hay que saber, 165-216. Bogotá: Aguilar, Altea, Taurus, Alfaguara, 2011.

Ceballos Gómez, Diana Luz Ed. Prácticas, territorios y representaciones en Colombia 18491960. Medellín: Universidad Nacional de Colombia, 2009.

Ceballos Gómez, Diana Luz. Simbolismo y saber: el circuito de la cultura. Medellín: Universidad Nacional de Colombia, 2018. 


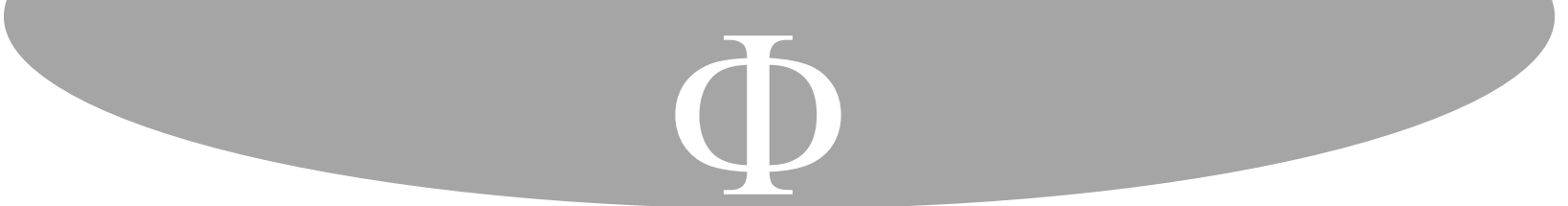

Investigaciones Sociológicas, 1979.

Goff, James E. The Persecution of Protestant Christians in Colombia, 1948-1958. Cuernavaca: CIDOC, 1968.

González González, Fernán E. Poderes enfrentados. Iglesia y estado en Colombia. Santafé de Bogotá: CINEP, 1997.

González, Justo L. Historia del cristianismo: desde la era de la reforma hasta la era inconclusa, Tomo 2. Miami: Unilit, 1994.

Gutiérrez, Benjamín F. «La influencia de John Mackay en las iglesias de América Latina y el Caribe. Entrevistas con personas que lo conocieron personalmente». Vida y Pensamiento 2, Vol. 30 (2010): 49-74.

Gutiérrez de Pineda, Virginia. Estructura, función y cambio de la familia en Colombia. Medellín: Universidad de Antioquia, 1999.

Gutiérrez de Pineda. Virginia, La familia en Colombia. Trasfondo histórico. Medellín: Universidad de Antioquia, 1997.

Gutiérrez Sánchez, Tomás de Jesús. «Protestantismo y política en América Latina una interpretación desde las ideologías políticas. Siglo XX». Tesis doctoral, Universidad Nacional Mayor de San Marcos, 2017.

Gutiérrez, Tomás J. «De Panamá a Quito: los congresos evangélicos en América Latina. Iglesia, misión e identidad (1916-1992)». Boletín Teológico 50-60, Año 27 (1995): 44-56.

Guzmán, Germán, Orlando Fals Borda, Eduardo Umaña Luna. La violencia en Colombia. Estudio de un proceso social, Tomo I. Bogotá: Universidad Nacional de Colombia, 1962.

Iglesia Presbiterio del Sur. «Colombia Presbyterian Church in celebration of the 160 years». Video de Youtube, 2:19:27. Publicado el 13 de septiembre de 2016. Consultado el 2 de febrero de 2020. https://www.youtube.com/watch?v=py_87ss0VOc .

Jaramillo Uribe, Jaime. Historia de la pedagogía como historia de la cultura, $2^{\mathrm{a}}$ edición. Bogotá: Centro de Investigación y Educación Cooperativas - CIEC, 1978.

Javier Voelkel, entrevistado por Luis Eduardo Ramírez, Medellín, julio 13 de 2015 y agosto 16 de 2017.

Koll, Karla Ann. «The Theology of John A. Mackay as Preparatio Liberationis». Theology Today 2, Vol. 73 (2016): 105-116.

Kuyper, Abraham. Lectures on Calvinism. Grand Rapids: Eerdmans, 1976.

La Defensa, «El excelentísimo Sr. Builes rectifica a los periódicos liberales», Medellín, septiembre 1 de 1950.

La Defensa, «El protestante en Colombia es automáticamente liberal. Además distribuye en el país propaganda comunista», Medellín, septiembre 8 de 1953.

La Defensa, «El protestantismo, su historia y sus errores por Monseñor Miguel Ángel Builes», Medellín, noviembre de 1953.

León de Leal, Magdalena Ed. La mujer y el desarrollo en Colombia. Bogotá: ACEP, 1977.

Lloyd-Jones, Martyn. Los puritanos. Sus orígenes y sucesores. Traducido por David Cánovas Williams. Edimburgo: Estandarte de la Verdad, 2013.

Mackay, John Alexander. «Bonn 1930 - and after: A Lyrical Tribute to Karl Barth». Theology Today 3, Vol. 13 (1956): 287-294.

Mackay, John Alexander. «On the Road: Twenty-Fifth Article in the Series How My Mind Has Changed in This Decade». The Christian Century 28 Vol. 56 (1939): 873-875.

Mackay, Juan A. El sentido presbiteriano de la vida: lo que significa vivir y adorar como 
presbiteriano, Trad. Abel Clemente. Englewood: Prentice Hall, S.f.

Mackay, Juan A. Las Iglesias Latinoamericanas y el Movimiento Ecuménico. New York: CCAL, 1963.

Mahecha, Guidoberto. «John Alexander Mackay 1889-1983». Vida y Pensamiento 2, Vol. 30 (2010): 7-28.

Marsden, George M. «Introduction: Reformed and American». En Reformed Theology in America. A History of its Modern Development, editado por David F. Wells, 1-12. Grand Rapids: Baker Books, 1997.

Meneses, Hernán J. «In memoriam Reverendo Aristóbulo Porras». En Primera Iglesia Presbiteriana de Bogotá, Príncipe de Paz 150 años. Dirigido por Germán Ezequiel Suárez Núñez, 86-89. Bogotá: Buena semilla, 2006.

Mondragón, Carlos. Leudar la masa. El pensamiento social de los protestantes en América Latina: 1920-1950. Buenos Aires: Kairós, 2005.

Montenegro, Armado y Rafael Rivas. Las piezas del rompecabezas. Desigualdad, pobreza y crecimiento. Bogotá: Taurus, 2005.

Moorhead, James H. «The Ecumenical Vision of John A. Mackay». Theology Today 3, Vol. 71 (2014): 276-291.

Moreno, Pablo. «La educación protestante durante la modernización de la educación en Colombia 1869-1928». Cristianismo y Sociedad 107 (1991): 51-71.

Murillo Posada, Amparo. «La modernización y las violencias (1930-1937)». En Historia de Colombia. Todo lo que hay que saber, Luis Enrique Rodríguez Baquero, et al., 265-310. Bogotá: Aguilar, Altea, Taurus, Alfaguara, 2011.

Negrete, Víctor. «A la memoria del maestro Orlando Fals Borda: bases y desarrollo de la Investigación-Acción Participativa en Córdoba (Colombia)». International Journal of Psychological Research 2, Vol. 1 (2008): 85-97.

Noll, Mark A. «The Princeton Theology». En Wells, David F. Ed. Reformed Theology in America. A History of its Modern Development, 13-35. Grand Rapids: Baker Books, 1997.

Núñez, Emilio A. Teología de la Liberación. Una perspectiva evangélica. San José: Caribe, 1986.

Olson, Roger E. The Story of Christian Theology. Twenty Centuries of Tradition and Reform. Downers Grove: InterVarsity Press, 1999.

Ordóñez, Francisco. Historia del cristianismo evangélico en Colombia. Bogotá: ClC, 1956.

Ortega y Gasset, José. Historia como sistema. Madrid: Espasa-Calpe, 1971.

Osorio Jaramillo, Oscar. Monseñor Builes un profeta de acontecer nacional. Medellín: S.n., 1988.

Ospina, Eduardo. Las sectas protestantes en Colombia: breve reseña histórica. Bogotá: Imprenta Nacional, 1953.

Palacios, Marco y Frank Stafford. Colombia: país fragmentado, sociedad dividida. Su historia. Bogotá: Norma, 2002.

Parker, Christian. Otra lógica en América Latina, Religión popular y modernización capitalista. México: Fondo de Cultura Económica, 1993.

Pérez Prieto, Victorino. «Los orígenes de la Teología de la Liberación en Colombia: Richard Shaull, Camilo Torres, Rafael Ávila, "Golconda", sacerdotes para América Latina, cristianos por el socialismo y comunidades eclesiales de base». Cuestiones Teológicas 99, Vol. 43 (2016): 73-108. 


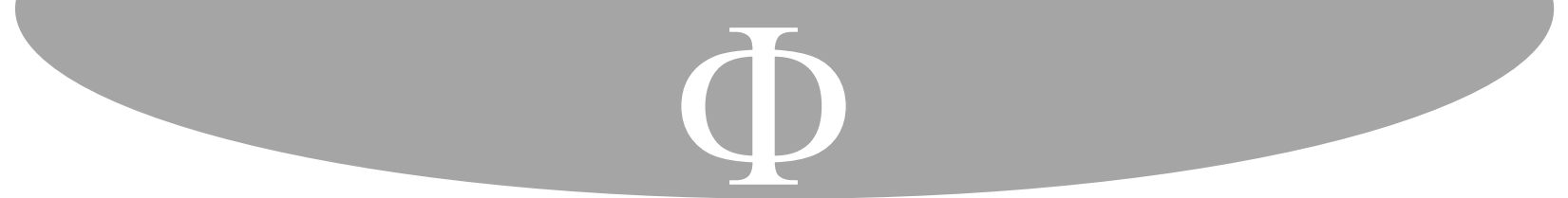

The Fifty-Ninth Annual Report of the Board of Foreign Missions of the Presbyterian Church of the United States of America. New York: Presbyterian Church the USA, 1896.

The Historical Society Prattsburgh. «Narcissa Prentiss Whitman». Consultada en agosto 7 , 2019. http://historyofprattsburgh.com/2011/02/narcissa-prentiss-whitman/.

Tirado Mejía, Álvaro. Los años sesenta. Una revolución en la cultura. Bogotá: Debate, 2014.

Troeltsch, Ernst. The Social Teaching of the Christian Churches, Vol. 1. Traducido por Olive Wyon. Londres: George Allen and Unwin Ltd, 1949.

Uribe Botero, Ángela. «¿Puede el uso de metáforas ser peligroso? Sobre las pastorales del monseñor Miguel Ángel Builes». Revista de Estudios Sociales 34 (2009): 113-122.

Vega, Liberato J. Perfíl de luces: un tributo a Colombia. Miami: LJV, 1989.

Velásquez Toro, Magdala dir. Las mujeres en la historia de Colombia. Tomo I Mujeres, historia y política. Santafé de Bogotá: Norma, 1995.

Vizcaíno G., Milcíades. «De la realidad a la utopía: una incursión por la vida y obra de Orlando Fals Borda». Espacio Abierto 4, Vol. 17 (2008): 569-594.

Wagner, Peter C. Dir. Latin American Theology. Radical or evangelical? The struggle for the faith in a Young church. Grand Rapids: Eerdmans, 1970.

Weber, Max. Economía y sociedad. Esbozo de sociología comprensiva. Traducido por José Medina Echavarría, Juan Roura Farella, Eugenio Ímaz, Eduardo García Maynez y José Ferrater Mora. México: Fondo de Cultura Económica, 1999.

Weber, Max. Sociología de la religión, $2^{\mathrm{a}}$ edición. Traducido por Ariel Navarro. México: Ediciones Coyoacán, 1999.

Wheeler, W. Reginald y Webster E. Browning. Modern Missions on the Spanish Main. Impressions of Protestant Work in Colombia and Venezuela. Philadelphia: The Westminster Press, 1925.

Williford, Thoma J. Laureano Gómez y los masones 1936-1942. Bogotá: Planeta, 2005.

Zwaanastra, Henry. «Louis Berkhof». En Reformed Theology in America. A History of its Modern Development. Editado por David F. Wells, 133-153. Grand Rapids: Baker Books, 1997.

Enviado: 31 de enero de 2021

Aceptado: 23 de marzo de 2021 